\title{
Transforming growth factor- $\alpha$ activates pancreatic stellate cells and may be involved in matrix metalloproteinase-1 upregulation
}

\author{
Hiroki Tahara ${ }^{1}$, Ken Sato ${ }^{1}$, Yuichi Yamazaki ${ }^{1}$, Tatsuya Ohyama ${ }^{1}$, Norio Horiguchi $^{1}$, Hiroaki Hashizume ${ }^{1}$, \\ Satoru Kakizaki ${ }^{1}$, Hitoshi Takagi ${ }^{1}$, Iwata Ozaki ${ }^{2}$, Hideo Arai ${ }^{3}$, Junko Hirato ${ }^{3}$, Ralf Jesenofsky ${ }^{4}$, Atsushi Masamune ${ }^{5}$ \\ and Masatomo Mori ${ }^{1}$
}

The role that transforming growth factor- $\alpha$ (TGF- $\alpha$ ) has in chronic pancreatitis and pancreatic cancer has not been fully elucidated. We evaluated the effects of TGF- $\alpha$ on the human pancreatic stellate cell (PSC) line RLT-PSC and primary human PSCs, and the expression levels of TGF- $\alpha$ and metalloproteinase-1 (MMP-1) in human chronic pancreatitis and pancreatic cancer tissues. TGF- $\alpha$ stimulated the proliferation and migration of PSCs. Although the mRNA expression levels of tissue inhibitor of metalloproteinase-1 and $\alpha 1(\mathrm{I})$ collagen were unchanged, the mRNA expression levels of MMP-1 increased concomitant with increases in MMP- 1 protein levels and collagenase activity. TGF- $\alpha$-stimulated migration of RLT-PSC cells was partially blocked by tissue inhibitor of metalloproteinase- 1 protein and MMP-1 small interfering RNA. MMP-1 was also observed to stimulate the migration of PSCs. TGF- $\alpha$-induced MMP-1 expression was completely blocked by gefitinib in PSCs. The Ras-ERK and PI3/Akt pathways appear to be involved in the activation of MMP-1 in PSCs. Immunohistochemical analyses showed that MMP-1 expression was significantly increased in the pancreatic interstitial tissues in case of chronic pancreatitis or pancreatic cancer compared with those in case of normal pancreas. In conclusion, TGF- $\alpha$ increased proliferation and migration of PSCs. TGF- $\alpha$-induced migration of cells may be partly due to upregulation of MMP- 1 . TGF- $\alpha$ and MMP-1 upregulation may contribute to the pathogenesis of chronic pancreatitis and pancreatic cancer. Laboratory Investigation (2013) 93, 720-732; doi:10.1038/labinvest.2013.59; published online 22 April 2013

KEYWORDS: pancreatic cancer; pancreatic fibrosis; PI3/Akt; primary PSC; Ras-ERK; RLT-PSC

Pancreatic stellate cells (PSCs) are myofibroblast-like cells, and they are one of the several types of resident cells in the exocrine pancreas. ${ }^{1-5}$ PSCs are localized to the periacinar, perivascular, and periductal regions of the pancreas, ${ }^{3,4,6-9}$ and have an important role in the pathobiology of chronic pancreatitis (CP) and pancreatic cancer. ${ }^{1-5}$ In these clinical settings, PSCs take part in disease pathogenesis following transformation from a quiescent state into an activated or 'myofibroblastic' state. ${ }^{1-5}$ PSCs are controlled by autocrine and paracrine stimuli and have similarities to hepatic stellate cells. ${ }^{1-5}$

Transgenic mice that express transforming growth factor- $\alpha$ (TGF- $\alpha$ ) display histological changes similar to those seen in
CP, despite the absence of inflammatory cells. ${ }^{10-12}$ TGF- $\alpha$ and its receptor, epidermal growth factor receptor (EGFR), are expressed at high concentrations in pancreatic ductal and acinar cells during CP. ${ }^{13}$ Another EGFR ligand, heparinbinding EGF, regulates both chemoattraction of PSCs and stimulation of PSC proliferation through EGFR signaling. ${ }^{14}$ Transgenic mice that ectopically express TGF- $\alpha$ in pancreatic acinar cells develop tubular metaplasia, a potentially premalignant lesion of the pancreatic ductal epithelium, ${ }^{11,12}$ and TGF- $\alpha$ causes significant stimulation of soft agar growth in two human pancreatic adenocarcinoma cell lines. ${ }^{15}$ Additionally, EGFR is considered to be a promising therapeutic target for pancreatic cancer. ${ }^{16}$ Thus, TGF- $\alpha$ may

\footnotetext{
'Department of Medicine and Molecular Science, Gunma University Graduate School of Medicine, Maebashi, Gunma, Japan; '2Department of Internal Medicine, Saga Medical School, Saga, Saga, Japan; ${ }^{3}$ Department of Pathology, Gunma University Hospital, Maebashi, Gunma, Japan; ${ }^{4}$ Department of Medicine II, Medical Faculty of Mannheim, University of Heidelberg, Mannheim, Germany and ${ }^{5}$ Division of Gastroenterology, Tohoku University Graduate School of Medicine, Aoba-ku, Sendai, Japan Correspondence: Dr K Sato, MD, PhD, Department of Medicine and Molecular Science, Gunma University Graduate School of Medicine, 3-39-22 Showa-machi, Maebashi, Gunma 371-8511, Japan.
}

E-mail: satoken@showa.gunma-u.ac.jp

Received 8 August 2012; revised 19 March 2013; accepted 19 March 2013 
contribute to the pathogenesis of $\mathrm{CP}$ and pancreatic cancer. Although one preliminary study ${ }^{7}$ found that TGF- $\alpha$ increases cellular fibronectin synthesis in PSCs without serum or at low serum concentrations, the role of TGF- $\alpha$ in PSCs has not been well studied.

In this study, we examined how TGF- $\alpha$ affects the human PSC line RLT-PSC and human primary PSCs and which signal-transduction pathways are induced by TGF- $\alpha$ in vitro. TGF- $\alpha$ has been shown to increase metalloproteinase-1 (MMP-1) expression in hepatic stellate cells, ${ }^{17}$ and when cocultured with PSCs, pancreatic cancer cells increase the expression of Runt-related transcription factor-2 to regulate MMP- $1 .{ }^{18}$ Therefore, we also investigated the role of MMP-1 in these processes. Finally, we examined the expression levels of TGF- $\alpha$ and MMP- 1 in human pancreatic tissues, including $\mathrm{CP}$ and pancreatic cancer samples.

\section{MATERIALS AND METHODS Chemicals and Reagents}

The ISOGEN RNA extraction reagent was purchased from Wako Pure Chemical Industries (Osaka, Japan). Reagents for the cell proliferation enzyme-linked immunosorbent assay (ELISA) and 5-bromo-2-deoxyuridine assay were purchased from Roche Applied Science (Tokyo, Japan). The Transcriptor First Strand cDNA Synthesis Kit was purchased from Roche Diagnostics K.K. (Tokyo, Japan). Dulbecco's modified Eagle's medium (DMEM)/F12 was purchased from Invitrogen (Tokyo, Japan). The BCA Protein Assay Kit was purchased from Thermo Fisher Scientific K.K. (Kanagawa, Japan). The human MMP-1 monoclonal antibody was purchased from Daiichi Fine Chemical (Toyama, Japan). Gefitinib, a selective inhibitor of EGFR tyrosine kinase, was purchased from Toronto Research Chemicals (North York, Ontario, Canada). The PI3 kinase inhibitors (LY294002 and wortmannin), mitogen-activated protein kinase kinase 1 (MEK1) inhibitor (PD98059), p38 mitogen-activated protein kinase inhibitor (SB203580), and 3-(4,5-dimethyl-thiazole-2yl)-2,5-diphenyl tetrazolium bromide (MTT) were purchased from Sigma-Aldrich (Saint Louis, MO, USA). TGF- $\alpha$, recombinant human MMP-1, and recombinant tissue inhibitor of metalloproteinase-1 (TIMP-1) were purchased from R\&D Systems (Minneapolis, MN, USA). The antibodies for phospho-extracellular signal-regulated kinase (ERK) $1 / 2$, ERK1/2, phospho-p38, and p38 were purchased from BD Biosciences (San Jose, CA, USA). The antibodies for phospho-c-Raf, c-Raf, and actin were purchased from Cell Signaling Technology (Beverly, MA, USA). The antibodies for EGFR, phospho-Akt, Akt, and TGF- $\beta 1$ were purchased from Santa Cruz Biotechnology (Santa Cruz, CA, USA). The MMP-1 human monoclonal antibody was purchased from Daiichi Fine Chemical (Toyama, Japan). The pcDNA3.1 vector containing a $2.2-\mathrm{kb}$ fragment of the MMP-1 promoter (derived from pCLCAT3 (ref. 19))/luciferase construct (derived from pGL3) and pRL-SV40 plasmid were used for measuring MMP-1 promoter activity in this study.
The following constructs were purchased from Biomyx Technology (San Diego, CA, USA): pMEV-MEK1-WT as a wild-type MEK-transfected control (WT-MEK); pMEV-MEK1-DN as a dominant-negative MEK mutant (DN-MEK); pMEV2HA-AKT1-WT as a wild-type Akttransfected control (WT-Akt) and pMEV2HA-AKT1-K179A as a dominant-negative Akt mutant (DN-Akt). The MMP-1 small interfering RNA (siRNA) was purchased from Life Technologies Japan (Tokyo, Japan).

\section{Cell Culture}

Briefly, an immortalized human PSC line, RLT-PSC, ${ }^{20}$ were cultured overnight at $1 \times 10^{6}$ cells/dish in $10-\mathrm{cm}$ dishes in DMEM supplemented with $10 \%$ fetal bovine serum, $50 \mu \mathrm{g} / \mathrm{ml}$ gentamycin and $250 \mathrm{ng} / \mathrm{ml}$ amphotericin B. For western blotting analysis, RLT-PSC cells were cultured overnight at $1 \times 10^{6} \mathrm{cells} /$ dish in $10-\mathrm{cm}$ dishes. The cells were incubated in a $95 \%$ air, $5 \% \mathrm{CO}_{2}$ humidified atmosphere at $37^{\circ} \mathrm{C}$, and cultured for 24 or $48 \mathrm{~h}$ for experiments. At a subconfluent stage, cells were deprived of serum for $24 \mathrm{~h}$ in serum-free DMEM/F12 supplemented with $0.1 \%$ albumin. After serum deprivation, TGF- $\alpha$ was added, and the cells were incubated for 24 or $48 \mathrm{~h}$ before harvesting, after which they were used in every experiment except the migration assay. Treatment of the cells with TGF- $\alpha$ in the presence or absence of the various signal transduction inhibitors was performed in serum-free DMEM. These inhibitors included $100 \mathrm{nM}$ gefitinib, $10 \mu \mathrm{M}$ LY294002, $10 \mathrm{nM}$ wortmannin, $10 \mu \mathrm{M}$ PD98059, and $10 \mu \mathrm{M}$ SB203580.

Primary human PSCs were isolated from the resected pancreas tissue of patients undergoing operation for pancreatic cancer as previously described. ${ }^{21}$ Experiments were performed using cells from at least three independent preparations and those between passages three and nine after isolation. Cells were maintained in Ham's F12/DMEM supplemented with $10 \%$ heat-inactivated fetal bovine serum, penicillin sodium, and streptomycin sulfate. We incubated PSCs in serum-free medium for 24 or $48 \mathrm{~h}$ before the addition of experimental reagents.

\section{Cell Viability}

The cytotoxicity of different concentrations of TGF- $\alpha$ was evaluated using the MTT assay, as described elsewhere. ${ }^{22}$

\section{Cell Proliferation Assay}

Cell proliferation was evaluated by measuring BrdU incorporation during DNA synthesis using the Cell Proliferation ELISA kit according to the manufacturer's protocol.

\section{RNA Expression Analysis of PSCs}

Total RNA was isolated from the cell lysates of PSCs (RLT-PSC cells or primary human PSCs) by ISOGEN RNA extraction reagent, quantified by spectrophotometry, and reverse transcribed to cDNA. Then, the CDNA was used for PCR. It was amplified using iQ-SYBR Green Supermix 
(TOYOBO, Osaka, Japan) with specific oligonucleotide primers for target sequences or glyceraldehyde-3-phosphate dehydrogenase (for normalization). Water was used as the negative control. The specific oligonucleotide primers are shown in Table 1.

\section{Type I Collagenase Assay of PSCs}

Type I collagenase activity in the RLT-PSC cells or primary human PSCs culture media was determined using the type I collagenase assay kit (Primary Cell , Hokkaido, Japan) as described elsewhere. ${ }^{17}$

\section{MMP-1 Promoter Activity}

MMP-1 promoter activity was determined by transfecting cells with the pcDNA3.1 plasmid containing the luciferase gene driven by the MMP-1 promotor as mentioned above and pRL-SV40 plasmid. Transient transfection of RLT-PSC cells was performed with Lipofectin 2000 (Invitrogen) according to the manufacturer's protocol. Transfected cells were treated with TGF- $\alpha$ in the presence or absence of various inhibitors for $24 \mathrm{~h}$. Luciferase activity was measured using the Dual-Luciferase Reporter Assay System (Promega, Madison, USA) with a Turner Designs Model TD-20/20 Luminometer (Promega). The receptor-dependent enhancer activity was determined based on firefly luciferase activity normalized against Renilla luciferase activity.

\section{Western Blotting Analysis of PSCs}

After the RLT-PSC cells or primary human PSCs were treated with or without TGF- $\alpha$, they were washed with phosphatebuffered saline. The western blotting procedure is described in detail elsewhere. ${ }^{17}$ The following antibodies were used at the indicated concentrations: phospho-ERK1/2 antibody (1:1000), ERK1/2 antibody (1:5000), MMP-1 antibody (1:1000), actin antibody (1:200), phospho-cRaf1 antibody (1:1000), c-Raf antibody (1:1000), phospho-MEK1/2 antibody (1:1000), MEK1/2 antibody
(1:1000), phospho-Akt antibody (1:1000), and Akt antibody (1:1000). In another series of experiments, MMP-1 protein expression was analyzed by western blotting after the plasmids WT-MEK, DN-MEK, WT-Akt, or DN-Akt were transfected into RLT-PSC cells using Lipofectin 2000 (Invitrogen) according to the manufacturer's protocol.

\section{Migration Assay}

Migration assays were performed using a 24-well transwell migration insert (Corning Incorporated, NY, USA). The RLT-PSC cells or primary human PSCs were seeded at $3 \times 10^{4}$ cells/well in DMEM in the upper chamber and were incubated in a $95 \%$ air, $5 \% \mathrm{CO}_{2}$ humidified atmosphere at $37^{\circ} \mathrm{C}$ for $24 \mathrm{~h}$. The cells were then washed, and medium with or without TGF- $\alpha$ was added to the upper chamber. After $24 \mathrm{~h}$ of incubation, the number of cells found on the lower side of the membrane was counted. To stimulate migration, DMEM containing MMP- 1 or TGF- $\alpha$ was added to the upper chamber. To inhibit TGF- $\alpha$-induced migration, DMEM containing TIMP-1 (in addition to TGF- $\alpha$ ) was added to the upper chamber, or RLT-PSC cells transfected with MMP-1 siRNA were used. To transfect RLT-PSC cells with the MMP-1 siRNA, the cells were seeded at $3 \times 10^{4}$ cells/well in DMEM with $10 \%$ fetal bovine serum, and then $30 \mathrm{pmol} / \mathrm{well}$ of siRNA against MMP-1 or nonsense siRNA (Stealth RNAi Negative Control; Invitrogen, Carlsbad, CA, USA) was transfected using Lipofectamine RNAiMAX and Opti-MEM (Invitrogen). Cells that migrated to the bottom wells were fixed in 5\% paraformaldehyde for $10 \mathrm{~min}$ and stained with $0.5 \%$ crystal violet for $10 \mathrm{~min}$. The cells on the upper side of the insert membrane were rubbed with a cotton swab to eliminate unmigrated cells. For quantification, the number of migrated cells on the underside of the membrane was estimated based on the number of cells observed under a $\times 100$ magnification field. Six fields per insert were scored and averaged.

Table 1 Specific oligonucleotide primers for real-time polymerase chain reaction

\begin{tabular}{|c|c|c|}
\hline Species & Genes & Primer sequences \\
\hline \multirow[t]{6}{*}{ Human } & GAPDH & 5'-GAAGGTGAAGGTCGGAGTC-3', 5'-GAAGATGGTGATGGGATTTC-3' \\
\hline & TIMP-1 & 5'-CAGAAGTCAACCAGACCACCTTATACC-3', 5'-CGGTTGTGGGACCTGTGGAAGTATC-3' \\
\hline & TIMP-2 & 5'-GAATCGGTGAGGTCCTGTCCTGA-3', 5'-CCTGCACACAAGCCCGGATAAA-3' \\
\hline & TIMP-4 & 5'-AGACCTCACAGGCTCAGTCG-3', 5'-CATTCCTGCCAGTCAGCCTG-3' \\
\hline & $M M P-1$ & 5'-CTGCTTACGAATTTGCCGACAGAG-3', 5'-GCAGCATCGATATGCTTCACAGTT-3' \\
\hline & MMP-2 & 5'-CTCCTGACATTGACCTTGGCACCG-3', 5'-CGTCACAGTCCGCCAAATGAAC-3' \\
\hline
\end{tabular}




\section{Histological Analysis}

Surgical specimens were used, including 5 cases of normal pancreatic tissue, 12 cases of $\mathrm{CP}$, and 10 cases of pancreatic cancer. These diseases were diagnosed clinically and pathologically. The use of human tissue in research has been approved by Gunma University's ethics committee. Patient characteristics were shown in Table 2. Formalin-fixed, paraffin-embedded pancreas tissue specimens were fixed in $10 \%$ neutral buffered formalin and embedded in paraffin. The tissue specimens were stored at room temperature before histological analysis. For histological examination, the tissue specimens were stained with hematoxylin-eosin (HE). Immunohistochemical analysis of TGF- $\alpha$, MMP- $1, \alpha$-smooth muscle actin $(\alpha$-SMA), and glial fibrillary acidic protein

Table 2 Patient characteristics

\begin{tabular}{lllll}
\hline & & & Normal pancreas & \\
\hline Case & Age (years) & Sex & Baseline disease & Histology \\
\hline 1 & 71 & Male & Lower bile duct cancer & Stage \\
2 & 73 & Male & Lower bile duct cancer & II B \\
3 & 58 & Female & Pancreatic cancer & tub3 \\
4 & 77 & Female & Serous cystadenoma & tub2 \\
5 & 56 & Female & Metastasis from renal cell carcinoma & B
\end{tabular}

\begin{tabular}{lclc}
\hline & & Chronic pancreatitis & \\
\hline Case & Age (years) & Sex & Etiology \\
\hline 1 & 43 & Male & Alcoholic pancreatitis \\
2 & 66 & Male & Alcoholic pancreatitis \\
3 & 58 & Male & Alcoholic pancreatitis \\
4 & 48 & Male & Alcoholic pancreatitis \\
5 & 68 & Male & Alcoholic pancreatitis \\
6 & 54 & Male & Alcoholic pancreatitis \\
7 & 60 & Male & Alcoholic pancreatitis \\
8 & 55 & Male & Alcoholic pancreatitis \\
9 & 60 & Male & Alcoholic pancreatitis \\
10 & 85 & Male & Idiopathic pancreatitis \\
11 & 86 & Male & Idiopathic pancreatitis \\
12 & 57 & Female & Idiopathic pancreatitis \\
\hline
\end{tabular}

\begin{tabular}{|c|c|c|c|c|c|}
\hline \multicolumn{6}{|c|}{ Pancreatic cancer } \\
\hline Case & Age (years) & Sex & Location of cancer & Histology & Stage \\
\hline 2 & 58 & Female & Pancreatic head & tub2 & $\| \mathrm{B}$ \\
\hline 3 & 62 & Male & Pancreatic head & tub1 & $\| A$ \\
\hline 5 & 79 & Male & Pancreatic tail & tub2 & $\| \mathrm{A}$ \\
\hline 6 & 78 & Male & Pancreatic head & tub2 & $\| \mathrm{B}$ \\
\hline 7 & 78 & Female & Pancreatic head & tub2 & $\| \mathrm{B}$ \\
\hline 8 & 62 & Female & Pancreatic head & tub2 & $\| \mathrm{B}$ \\
\hline 9 & 71 & Male & Pancreatic body & tub1 & $\| B$ \\
\hline
\end{tabular}

Abbreviations: tub1, well-differentiated tubular adenocarcinoma; tub2, moderately differentiated tubular adenocarcinoma; tub3, poorly differentiated tubular adenocarcinoma. 
(GFAP) was performed using the avidin-biotin-peroxidase complex method, with appropriate antibodies. The sites of peroxidase binding were visualized using diaminobenzidine. The following antibodies were used at the indicated concentrations: MMP-1 (1:200), TGF- $\alpha$ (1:50), EGFR (1:20), $\alpha$-SMA (1:3200), and GFAP (1:5000). Ten microscopic views of the TGF- $\alpha$ - and MMP-1-stained areas were measured using the NIH ImageJ software package. For evaluation of the distribution of MMP-1, MMP-1-stained areas were compared with HE-, $\alpha$-SMA-, or GFAP-stained areas using the serial sections of the same tissue. No staining was confirmed when omitting primary antibodies as negative controls.

Double immunohistochemical staining was carried out to clarify the distribution of TGF- $\alpha$ and TGF- $\beta 1$ that has been well established as a potent profibrogenic factor for PSCs. After a blocking step, sections were incubated with anti-TGF$\beta 1$ antibody (1:100), followed by universal immune-alkalinephosphate polymer (Nichirei, Tokyo, Japan). Next, the sections were treated with fast red II substrate and were subsequently stained with anti-TGF- $\alpha$ antibody (1:50) followed by universal immune-alkaline-phosphate polymer. Then, they were treated with PermaBlue substrate.

\section{Statistical Analysis}

Data were analyzed using one-way analysis of variance tests except for part of the migration assay, which was analyzed using an unpaired, two-sided Student's $t$-test. Values are expressed as the mean \pm s.d. Unless otherwise
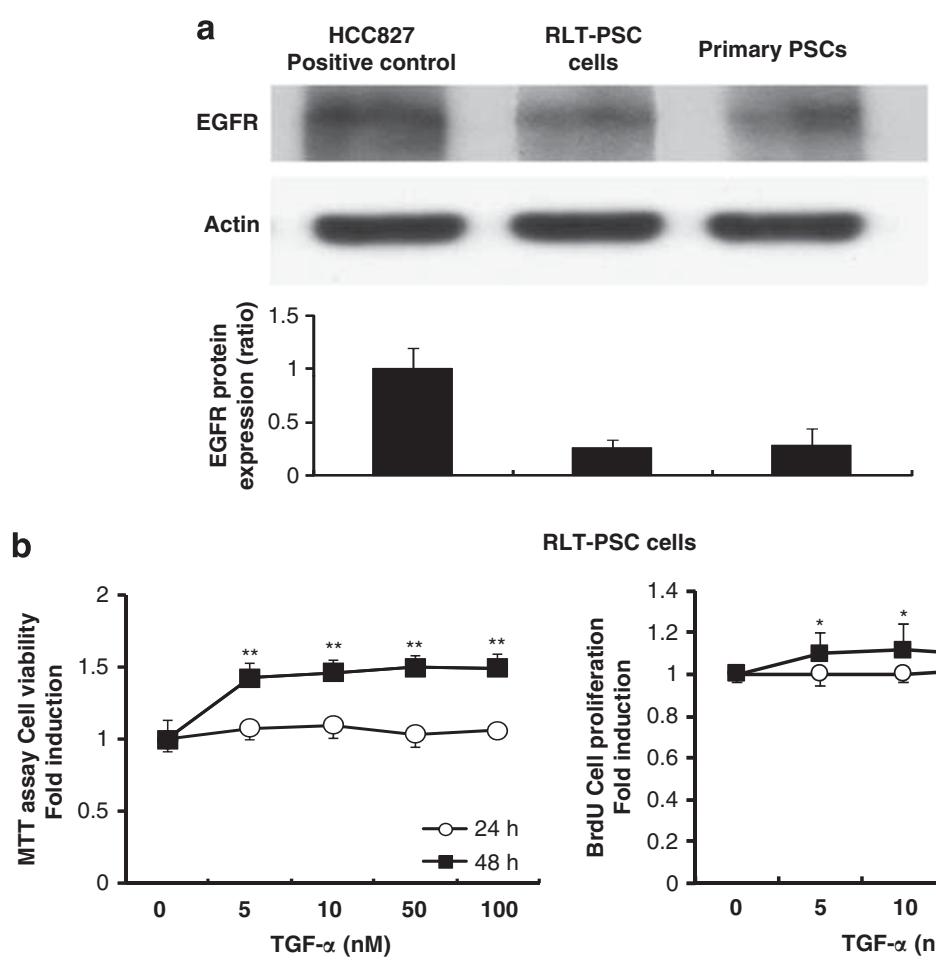

RLT-PSC cells

C



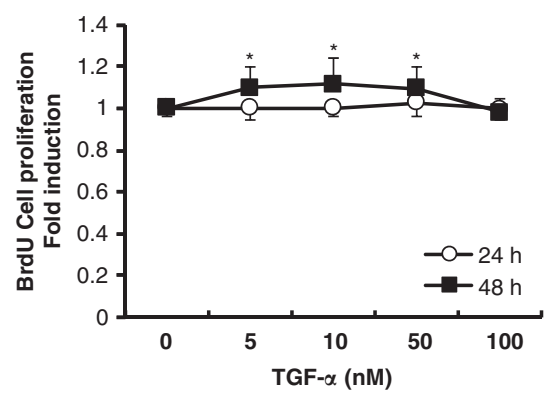

Primary PSCs

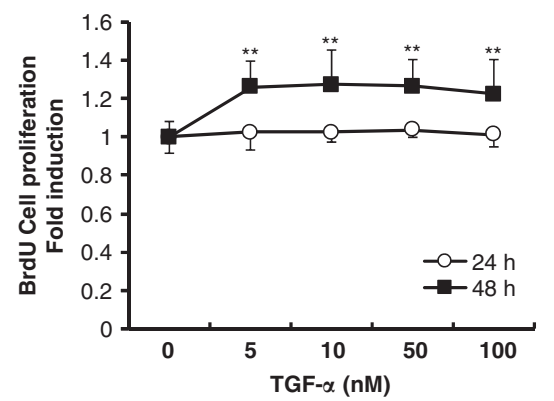

Figure 1 EGFR protein expression in RLT-PSC cells and primary pancreatic stellate cells (PSCs) (a) and the effects of transforming growth factor (TGF)- $\alpha$ on cell viability and proliferation of RLT-PSC cells (b) and primary PSCS (c). The human lung carcinoma cell line HCC827 was used as a positive control. Relative EGFR protein expression ratio was calculated by using the positive control. Cell viability was evaluated using a 3-(4,5-dimethyl-thiazole-2-yl)-2, 5-diphenyl tetrazolium bromide (MTT) assay, and cell proliferation was evaluated by measuring 5-bromo-2-deoxyuridine (BrdU) incorporation during DNA synthesis. The indicated concentrations of TGF- $\alpha$ were used during 24 and $48 \mathrm{~h}$ incubations. ${ }^{*} P<0.05$ and ${ }^{*} P<0.01$ vs the corresponding controls. Each experiment was performed on three separate occasions for forty-eight times. 
indicated, at least three independent experiments were performed for each assay.

\section{RESULTS}

\section{Confirmation of EGFR Expression in RLT-PSC Cells and Primary Human PSCs}

We first examined the expression of EGFR in immortalized human PSCs (RLT-PSC cells) and primary human PSCs. Primary human PSCs expressed typical activation markers including $\alpha$-SMA, vimentin, type I collagen, and fibronectin. ${ }^{23}$ After the passage, contamination of acinar cells was negligible, because acinar cells could not survive under the culture condition employed herein. Western blotting showed that both RLT-PSC cells and primary human PSCs expressed EGFR protein (Figure 1a).

\section{Effects of TGF- $\alpha$ on Cell Viability and Proliferation in RLT-PSC Cells and Primary Human PSCs}

Treatment of RLT-PSC cells (Figure 1b) and primary human PSCs (Figure 1c) with TGF- $\alpha$ for $24 \mathrm{~h}$ had no impact on cell viability or proliferation. In contrast, $48 \mathrm{~h}$ treatment increased cell viability at all of the indicated TGF- $\alpha$ concentrations in RLT-PSC cells (Figure 1b), while cell viability was generally enhanced with increasing concentrations of TGF- $\alpha$ but returned to control levels in primary human PSCs treated with $100 \mathrm{nM}$ TGF- $\alpha$ (Figure 1c). On the other hand, cell proliferation was generally enhanced with increasing concentrations of TGF- $\alpha$ but returned to control levels in RLT-PSC cells treated with $100 \mathrm{nM}$ TGF- $\alpha$ (Figure 1c), whereas cell proliferation was increased at all of the indicated TGF- $\alpha$ concentrations in primary human PSCs (Figure 1d). Thus, cell viability and proliferation in response a
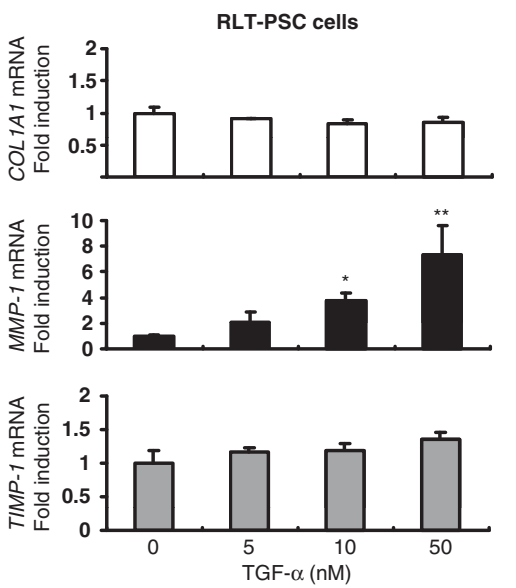

b
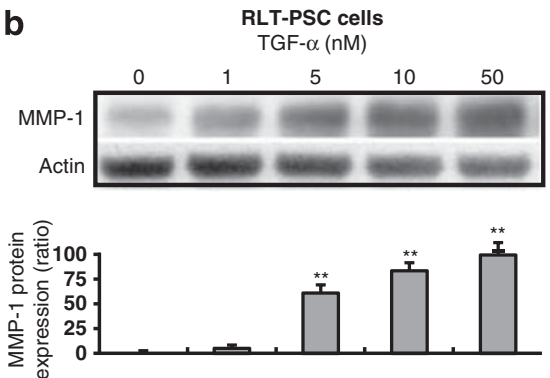

$\mathbf{C}$

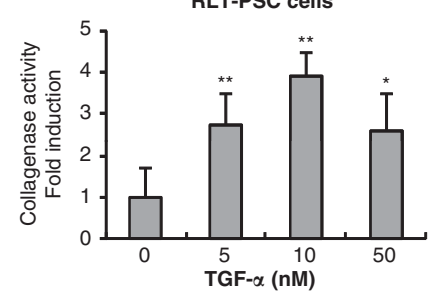

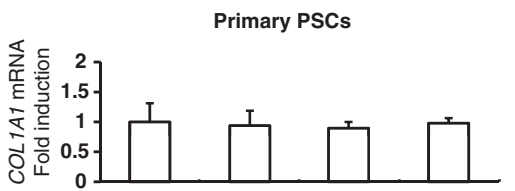
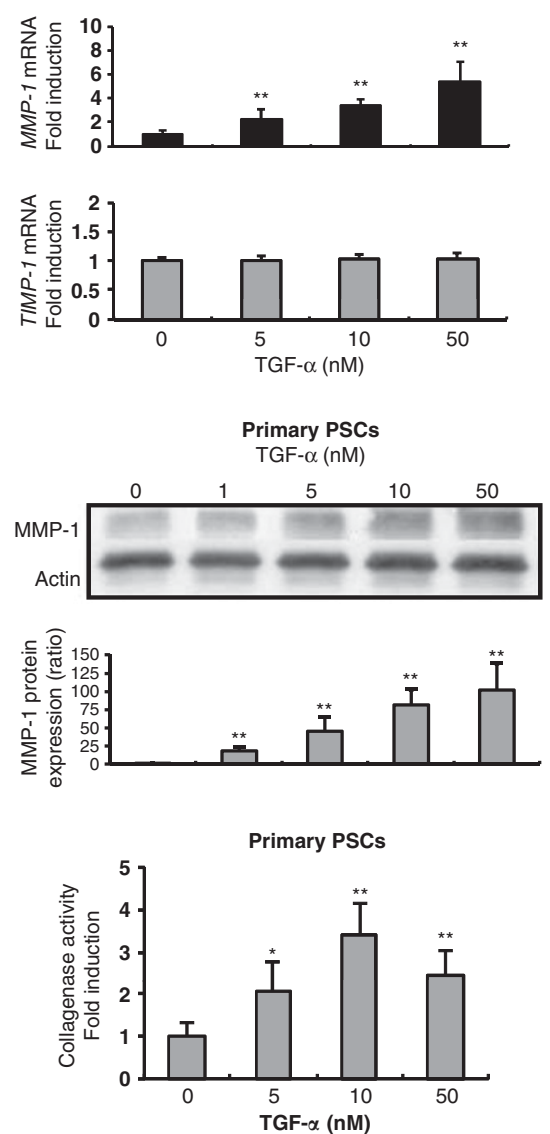

Figure 2 Transforming growth factor (TGF)- $\alpha$-induced mRNA expression of fibrosis-related genes (a) and expression of matrix metalloproteinase-1 (MMP-1) protein (b) and collagenase activity (c) in RLT-PSC cells and primary pancreatic stellate cells (PSCs). ${ }^{*} P<0.05$ and ${ }^{*} P<0.01$ vs the corresponding controls. The levels of mRNA expression were standardized to that of the glyceraldehyde-3-phosphate dehydrogenase (GAPDH) mRNA. 

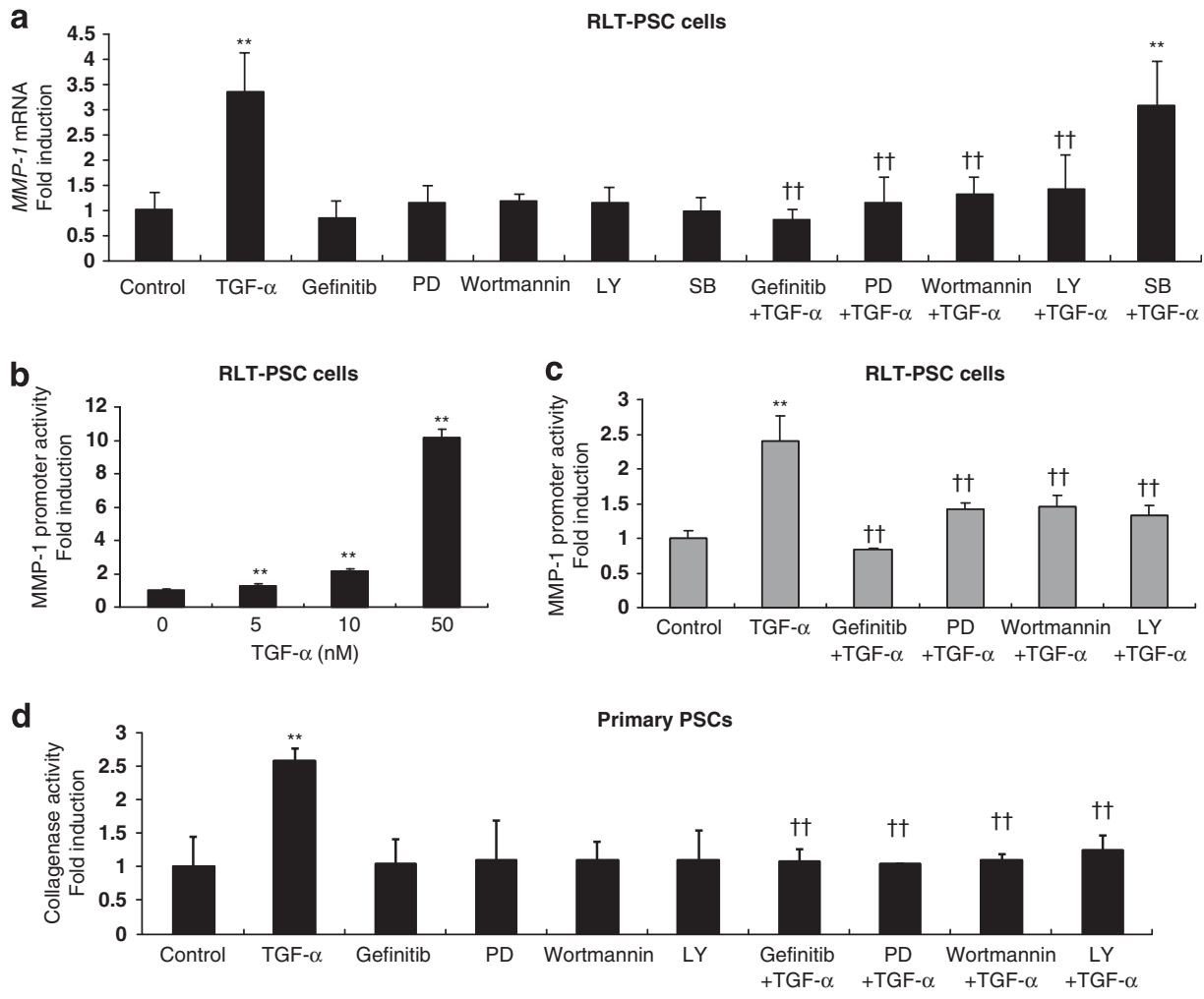

Figure 3 Transforming growth factor (TGF)- $\alpha$-induced matrix metalloproteinase-1 (MMP-1) mRNA expression and promoter activity and collagenase activity; the roles of the mitogen-activated protein kinase and PI3/Akt signal-transduction pathways on TGF- $\alpha$-induced MMP-1 mRNA expression, TGF- $\alpha$-induced MMP-1 promoter activity in RLT-PSC cells and TGF- $\alpha$-induced collagenase activity in primary pancreatic stellate cells (PSCs). (a) The effects of $100 \mathrm{nM}$ gefitinib (an EGFR inhibitor), $10 \mu \mathrm{M}$ PD98059 (a mitogen-activated protein kinase kinase 1 (MEK1) inhibitor, PD), $10 \mathrm{nM}$ wortmannin (a PI3 inhibitor), $10 \mu \mathrm{M} \mathrm{LY} 294002$ (a PI3 inhibitor; LY), and $10 \mu \mathrm{M}$ SB203580 (a p38 inhibitor; SB) on MMP-1 mRNA expression after stimulation with or without $10 \mathrm{nM}$ TGF- $\alpha$ in RLT-PSC cells. (b) The effects of TGF- $\alpha$ on MMP-1 promoter activity in RLT-PSC cells. (c) The effects of $100 \mathrm{nM}$ gefitinib, $10 \mu \mathrm{M}$ $\mathrm{PD}, 10 \mathrm{nM}$ wortmannin, and $10 \mu \mathrm{M} \mathrm{LY}$ on MMP-1 promoter activity after stimulation with $10 \mathrm{nM}$ TGF- $\alpha$ in RLT-PSC cells. (d) The effects of $100 \mathrm{nM}$ gefitinib, $10 \mu \mathrm{M}$ PD, $10 \mathrm{nM}$ wortmannin, and $10 \mu \mathrm{M} \mathrm{LY}$ on MMP-1 collagenase activity after stimulation with or without $10 \mathrm{nM}$ TGF- $\alpha$ in primary PSCs. ${ }^{*} P<0.01$ vs the corresponding controls; ${ }^{\dagger \dagger} P<0.01$ vs TGF- $\alpha$. The levels of mRNA expression were standardized to that of the glyceraldehyde-3phosphate dehydrogenase (GAPDH) mRNA.

to $100 \mathrm{nM}$ TGF- $\alpha$ for $48 \mathrm{~h}$ were somewhat different between RLT-PSC cells and primary human PSCs. Then, we treated the cells with up to $50 \mathrm{nM}$ TGF- $\alpha$ for the following experiments. Besides, to eliminate the proliferative effect caused by TGF- $\alpha$ on cells, we incubated the cells for only $24 \mathrm{~h}$ before the following experiments.

\section{TGF- $\alpha$ Increases the Expression of MMP-1 mRNA and Protein Levels as Well as MMP-1 Functional Activity in RLT-PSC Cells and Primary Human PSCs}

Treatment with various concentrations of TGF- $\alpha$ significantly increased MMP-1 gene expression in RLT-PSC cells and primary human PSCs in a concentration-dependent manner (up to $50 \mathrm{nM}$ TGF- $\alpha$; (Figure $2 \mathrm{a}$ )). In contrast, no significant differences were observed in the mRNA expression levels of $\alpha 1(I)$ collagen (COL1A1) and TIMP-1 between the cells treated with TGF- $\alpha$ and the control cells (Figure 2a). TIMP-2, TIMP-3, and TIMP-4 mRNA levels were not significantly changed, regardless of TGF- $\alpha$ concentration (data not shown).
MMP-2 mRNA levels were reduced in a concentrationdependent manner (Supplementary Figure 1). MMP-1 protein expression also increased in the cells in a concentrationdependent manner (up to $50 \mathrm{nM}$ TGF- $\alpha$ ) (Figure 2b). Consistent with these findings, MMP-1 collagenase activity increased following TGF- $\alpha$ treatment in a concentrationdependent manner (up to $10 \mathrm{nM}$ ), but the increase was attenuated at a concentration of $50 \mathrm{nM}$ TGF- $\alpha$ (Figure 2c).

\section{The Ras-ERK and PI3/Akt Pathways, but not the p38 Pathway, are Involved in MMP-1 mRNA Expression} in RLT-PSC cells

To evaluate the signaling pathways involved in TGF- $\alpha$ induced MMP-1 mRNA expression, we investigated the activation of the mitogen-activated protein kinase and PI3/Akt pathways in RLT-PSC cells (Figure 3a). Gefitinib (a selective inhibitor of EGFR tyrosine kinase) completely reversed TGF- $\alpha$-induced MMP-1 mRNA expression. The MEK1 inhibitor PD98059 and the PI3 kinase inhibitors 
a

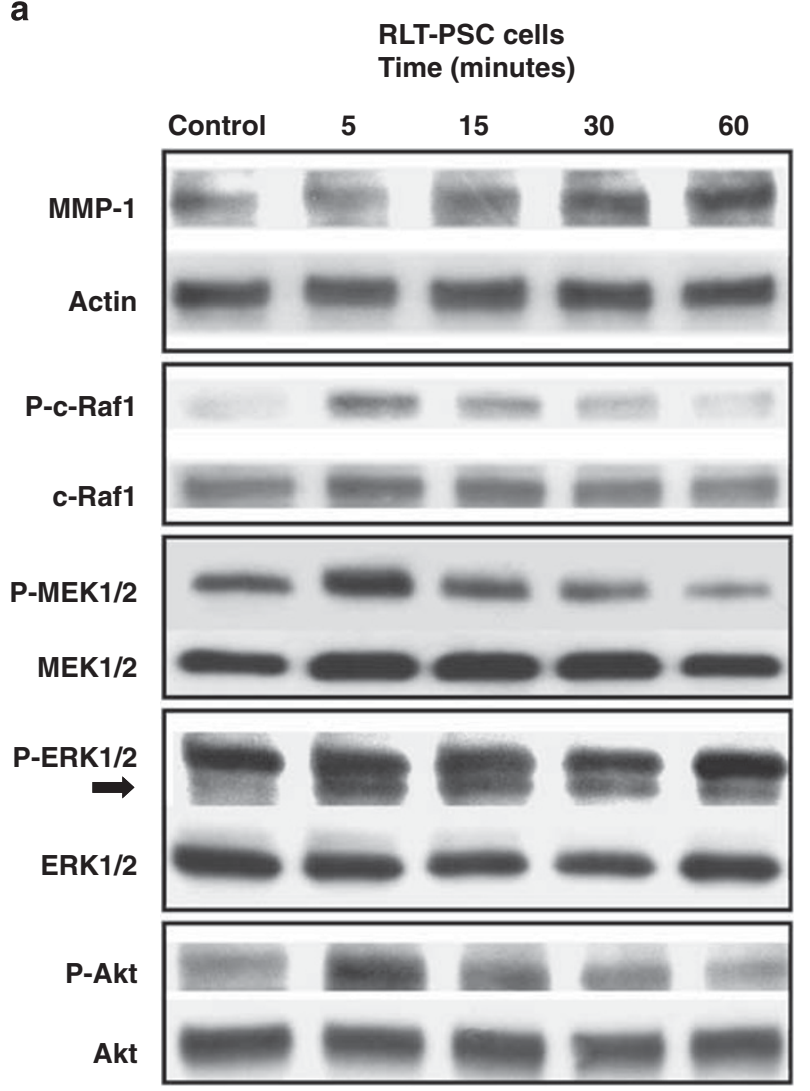

b
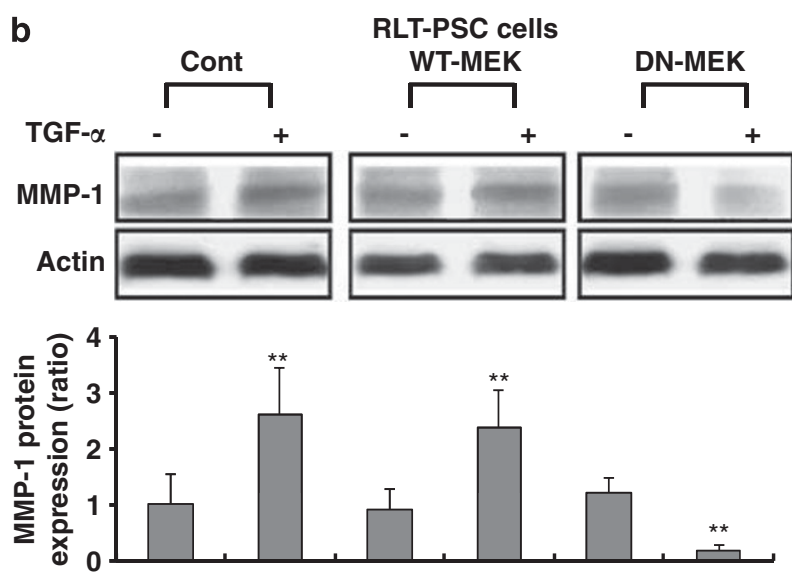

C

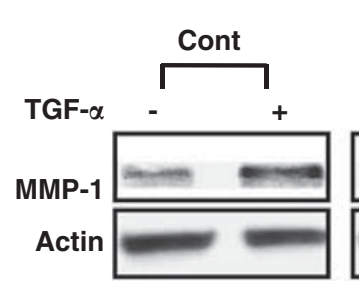

RLT-PSC cells
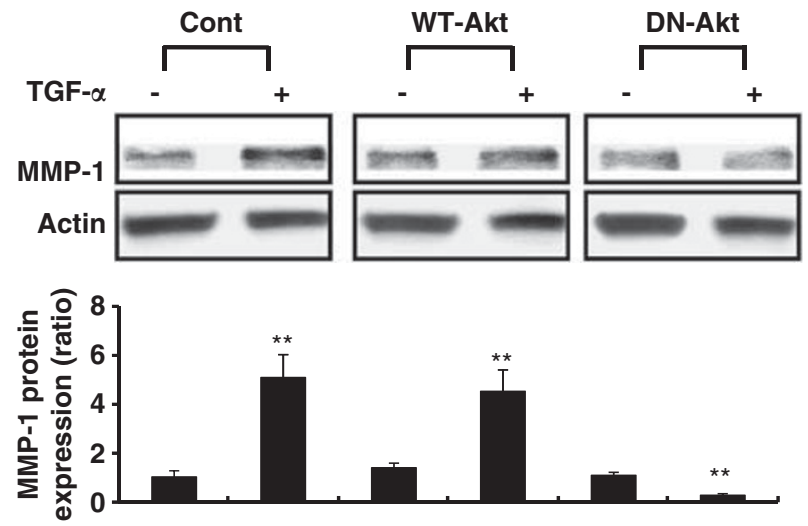

Figure 4 Time courses of transforming growth factor (TGF)- $\alpha$-induced matrix metalloproteinase-1 (MMP-1) protein expression; TGF- $\alpha$-induced phosphorylation of Ras-ERK and Akt in RLT-PSC cells; and the effects of transfection of dominant-negative MEK and Akt mutants on MMP-1 protein expression in RLT-PSC cells. (a) The effects of TGF- $\alpha$ on MMP-1 protein expression and phosphorylation of c-Raf1, mitogen-activated protein kinase (MEK)1/2, extracellular signal-regulated kinase (ERK)1/2 or Akt at different time points following the addition of $10 \mathrm{nM}$ TGF- $\alpha$. (b) RLT-PSC cells transfected with or without wild-type MEK (WT-MEK) or dominant-negative MEK (DN-MEK) with or without $10 \mathrm{nM}$ TGF- $\alpha$ are indicated. (c) RLT-PSC cells transfected with or without wild-type Akt (WT-Akt) or dominant-negative Akt (DN-Akt) with or without $10 \mathrm{nM}$ TGF- $\alpha$ are indicated. The levels of protein expression were standardized to those of the actin protein. ${ }^{* *} P<0.01$ vs the corresponding controls.

wortmannin and LY294002 significantly inhibited TGF- $\alpha$ induced MMP-1 mRNA expression, but the p38 inhibitor SB203580 did not significantly affect TGF- $\alpha$-induced MMP-1 mRNA expression. To ascertain whether the effects of TGF- $\alpha$ were specific to these assays, we evaluated the effects of TGF$\alpha$ on RLT-PSC cells using an MMP-1 promoter assay.

TGF- $\alpha$ Increases MMP-1 Promoter Activity in a Concentration-Dependent Manner, and the Ras-ERK and PI3/Akt Pathways are Involved in TGF- $\alpha$-induced MMP-1 Promoter Activity in RLT-PSC Cells

Treatment with various concentrations of TGF- $\alpha$ for $24 \mathrm{~h}$ led to significant increases in MMP-1 promoter activity in a concentration-dependent manner (Figure 3b). Gefitinib completely reversed TGF- $\alpha$-induced MMP-1 promoter activity, and PD98059, wortmannin, and LY294002 significantly inhibited this activity (Figure $3 \mathrm{c}$ ). To validate the signaling pathways involved in TGF- $\alpha$-induced MMP-1 activation, we evaluated the effects of TGF- $\alpha$ on primary human PSCs using an MMP-1 functional activity.

\section{The Ras-ERK and PI3/Akt Pathways are Involved in TGF- $\alpha$-induced MMP-1 Functional Activity in Primary Human PSCs}

Gefitinib completely reversed TGF- $\alpha$-induced MMP- 1 functional activity. PD98059, wortmannin, and LY294002 significantly inhibited TGF- $\alpha$-induced MMP-1 functional activity (Figure $3 \mathrm{~d}$ ).

\section{TGF- $\alpha$ Increases MMP-1 Protein Expression and} Phosphorylation of c-Raf1, MEK1/2, ERK1/2, and Akt, but not p38, in RLT-PSC Cells

TGF- $\alpha$ treatment increased expression levels of the MMP-1 protein over a period of $60 \mathrm{~min}$. TGF- $\alpha$-induced phosphorylation of c-Raf1, MEK1/2, ERK1/2, Akt, and p38 were examined in RLT-PSC cells. The time courses of MMP-1 protein expression, as well as c-Raf1, MEK1/2, ERK1/2, and 
a
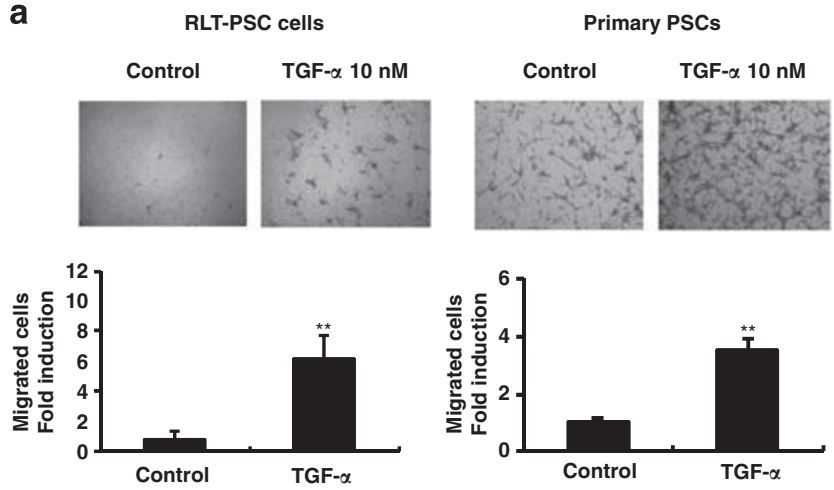

C

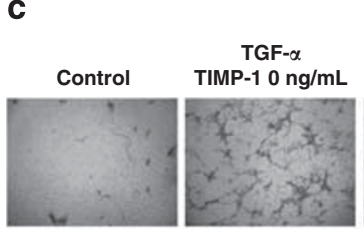

RLT-PSC cells

TGF- $\alpha$.

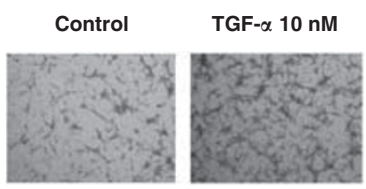

b
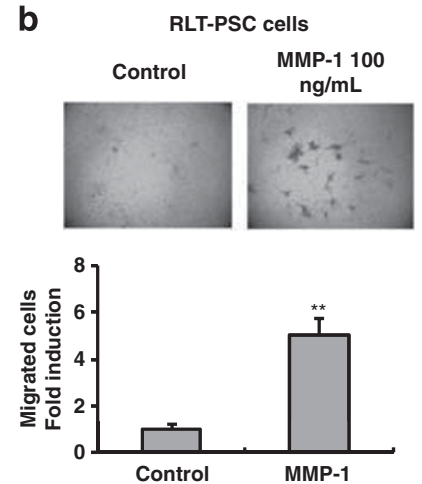

d


RLT-PSC cells
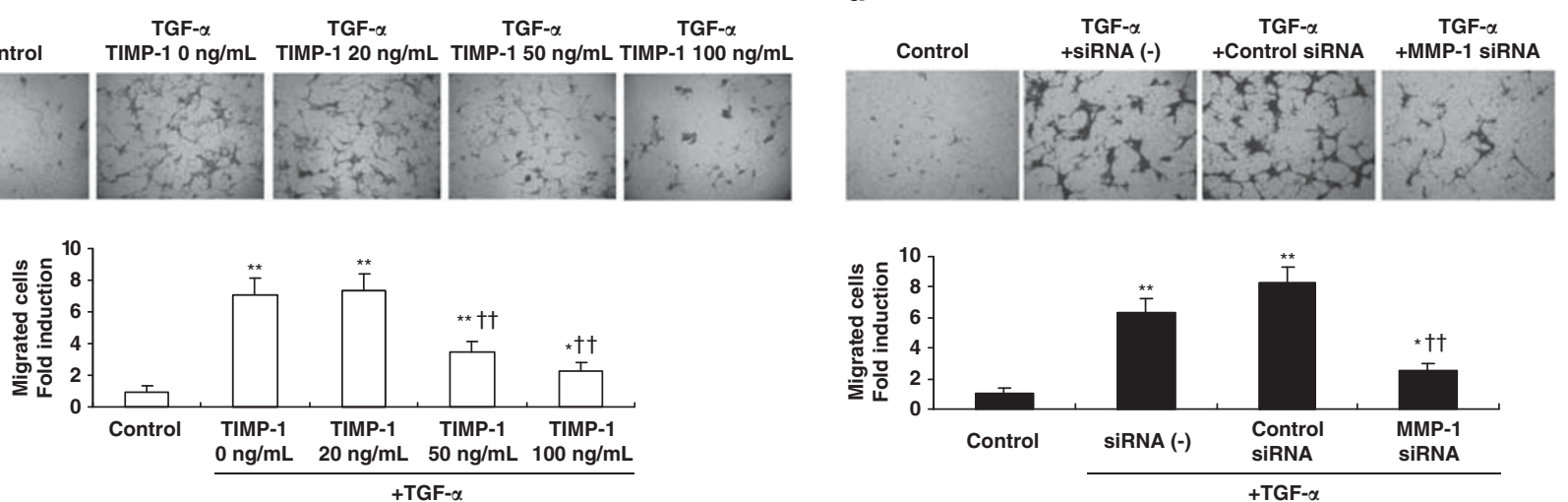

Figure 5 The effects of transforming growth factor (TGF- $\alpha$ ) (a) or matrix metalloproteinase-1 (MMP-1) (b) on the migration of RLT-PSC cells and primary pancreatic stellate cells (PSCs), and the effects of TIMP-1 protein (c) and an MMP-1 small interfering RNA (siRNA) (d) on TGF- $\alpha$-induced RLT-PSC cells migration. The concentrations of TGF- $\alpha$ and MMP-1 were $10 \mathrm{nM}$ and $100 \mathrm{ng} / \mathrm{ml}$, respectively. TIMP- 1 concentrations were as indicated. MMP- 1 and nonsense (control) siRNAs were used. ${ }^{*} P<0.05$ and ${ }^{* *} P<0.01$ vs the corresponding controls; ${ }^{\dagger \dagger} P<0.01$ vs TGF- $\alpha$ only.

Akt phosphorylation, are shown in Figure 4a. Maximal phosphorylation of c-Raf1, MEK1/2, ERK1/2, and Akt was observed $5 \mathrm{~min}$ following stimulation with $10 \mathrm{nM}$ TGF- $\alpha$. In contrast, p38 phosphorylation was not affected by TGF- $\alpha$ signaling (Supplementary Figure 2).

\section{RLT-PSC Cells Transfected with Dominant-negative MEK or Akt Mutants Exhibited Decreased MMP-1 Protein Expression}

Treatment with $10 \mathrm{nM}$ TGF- $\alpha$ significantly increased MMP-1 protein expression in RLT-PSC cells (Figures $4 \mathrm{~b}$ and $\mathrm{c}$ ). Transfection of RLT-PSC cells with WT-MEK (Figure 4b) or WT-Akt (Figure 4c) did not change MMP-1 protein expression compared with controls with or without TGF- $\alpha$. In contrast, transfection with the DN forms of these proteins, DN-MEK (Figure 4b) and DN-Akt (Figure 4c), abolished TGF- $\alpha$-induced MMP-1 upregulation.

TGF- $\alpha$ and MMP-1 Increase Migration of RLT-PSC Cells and Primary Human PSCs, and Migration of RLT-PSC cells is Inhibited by TIMP-1 or MMP-1 siRNA

Treatment with $10 \mathrm{nM}$ TGF- $\alpha$ (Figure 5a) or $100 \mathrm{ng} / \mathrm{ml}$ MMP-1 (Figure 5b) significantly increased migration of
RLT-PSC cells and primary human PSCs, and these results were analyzed using an unpaired, two-sided Student's $t$-test. TGF- $\alpha$-induced migration was significantly inhibited by TIMP-1 protein in a concentration-dependent manner (up to $100 \mathrm{ng} / \mathrm{ml}$ ) (Figure 5c), and migration was also inhibited by MMP-1 siRNA in RLT-PSC cells (Figure 5d). For the siRNA experiments, we first confirmed successful blockade of MMP-1 at the mRNA level (Supplementary Figure 3).

\section{TGF- $\alpha$ Expression in the Acinar and Ductal cells and} MMP-1 Expression in the Pancreatic Interstitial Tissues are Increased in CP or Pancreatic Cancer Compared with Normal Pancreatic Tissue

TGF- $\alpha$ expression was observed in the acinar, ductal cells, and cancer cells but not in the pancreatic interstitial tissue, whereas MMP-1 expression was observed in all four tissues. TGF- $\alpha$ expression in acinar and ductal cells significantly increased in $\mathrm{CP}$ or pancreatic cancer samples compared with normal pancreatic tissue (Figure 6a). MMP-1 expression in acinar and ductal cells was not significantly different between $\mathrm{CP}$, pancreatic cancer, or normal pancreatic samples. In contrast, MMP-1 expression was significantly increased in 

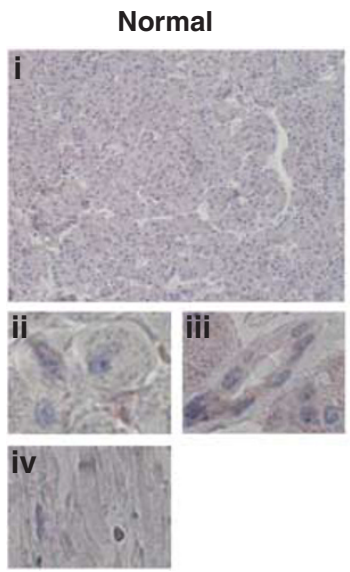

b
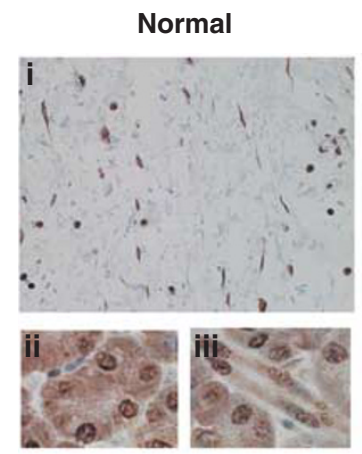


MMP-1

Chronic pancreatitis
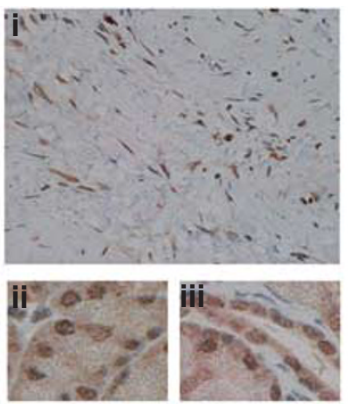
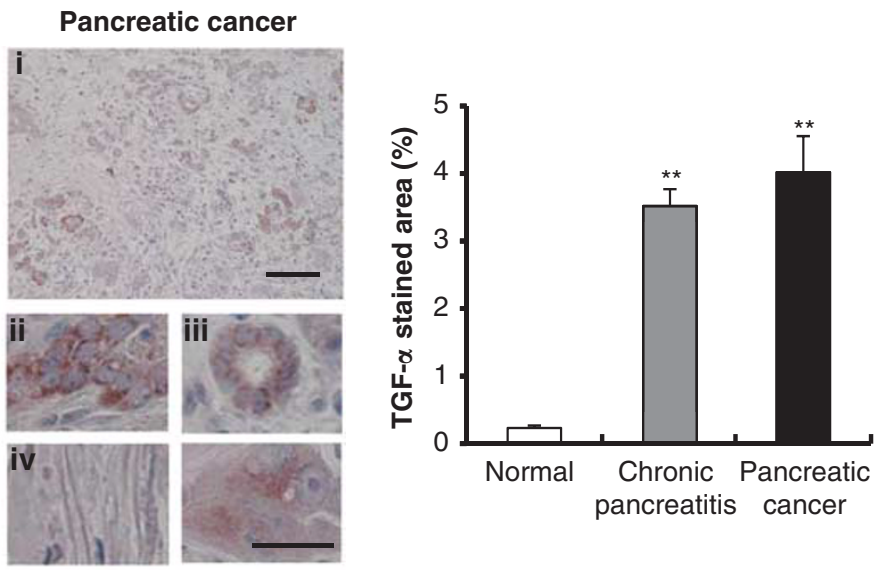

Pancreatic cancer

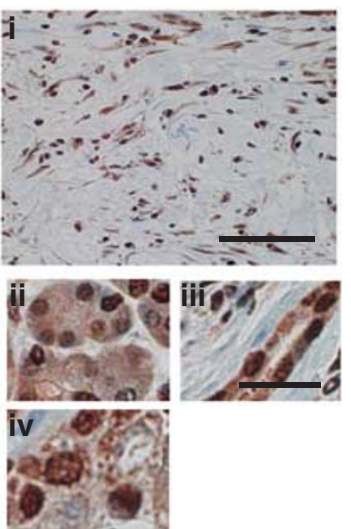

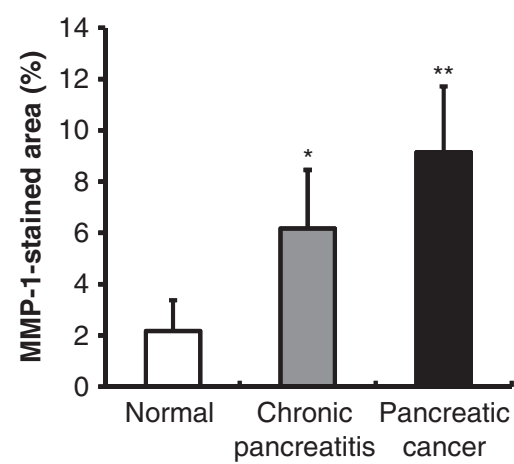

Figure 6 Transforming growth factor (TGF)- $\alpha$ expression and matrix metalloproteinase-1 (MMP-1) protein expression in the acinar cells, ductal cells, cancer cells, and pancreatic interstitial tissues of a normal pancreas, a chronic pancreas and a pancreatic cancer sample were evaluated by TGF- $\alpha$ (a) and MMP-1 (b) staining, respectively. In TGF- $\alpha$ staining (a), low-resolution histological image (i), acinar cells (ii), ductal cells (iii), interstitial tissues (iv), and cancer cells (v) are shown. In MMP-1 staining (b), interstitial tissues (i), acinar cells (ii), ductal cells (iii), and cancer cells (iv) are shown. Quantification of the TGF- $\alpha$ and MMP-1-stained areas. ${ }^{*} P<0.05$ and ${ }^{*} P<0.01$ vs normal pancreas. The scale bar in low-resolution histological images is $200 \mu \mathrm{m}$ (i). The scale bar in high-resolution histological images is $50 \mu \mathrm{m}$ (ii-v).

the pancreatic interstitial tissues in case of $\mathrm{CP}$ or pancreatic cancer compared with those in case of normal pancreas (Figure 6b).

\section{The Distribution of MMP-1 Partially Overlaps with that of $\alpha$-SMA and GFAP}

The distribution of MMP-1 partially overlapped with that of $\alpha$-SMA and GFAP in CP (Figure 7) and pancreatic cancer (Figure 8) samples.

\section{The Partial Colocalization of TGF- $\beta 1$ and TGF- $\alpha$}

The distribution of TGF- $\beta 1$ partially overlapped with that of TGF- $\alpha$ in CP and pancreatic cancer samples. The distribution of TGF- $\beta 1$ was also found in the interstitial tissues in CP and pancreatic cancer samples, differing from TGF- $\alpha$. Representative tissue sample of CP is shown in Figure 9.

\section{DISCUSSION}

The major finding of this study is that TGF- $\alpha$ promotes the proliferation and migration of PSCs. We found that in vitro addition of TGF- $\alpha$ to the culture medium of PSCs increased MMP-1 mRNA and protein expression, and enhanced MMP-1 functional activity. TGF- $\alpha$-induced activation of MMP-1 was confirmed by using primary PSCs. Given that TGF- $\alpha$ reduced mRNA expression of MMP- 2 in a concentration-dependent manner, the effects of MMP-2 on cell migration induced by TGF- $\alpha$ were considered to be not always high. TGF- $\alpha$-induced PSC migration was at least partly due to MMP-1 upregulation, as not only TGF- $\alpha$ but also MMP-1 were each sufficient to increase PSC migration. Furthermore, TGF- $\alpha$-induced migration of RLT-PSC cells was inhibited by both TIMP-1 protein and MMP-1 siRNA. In addition, the areas of MMP-1 expression partially overlapped with $\alpha$-SMA-stained areas (a marker of PSC activation) and 

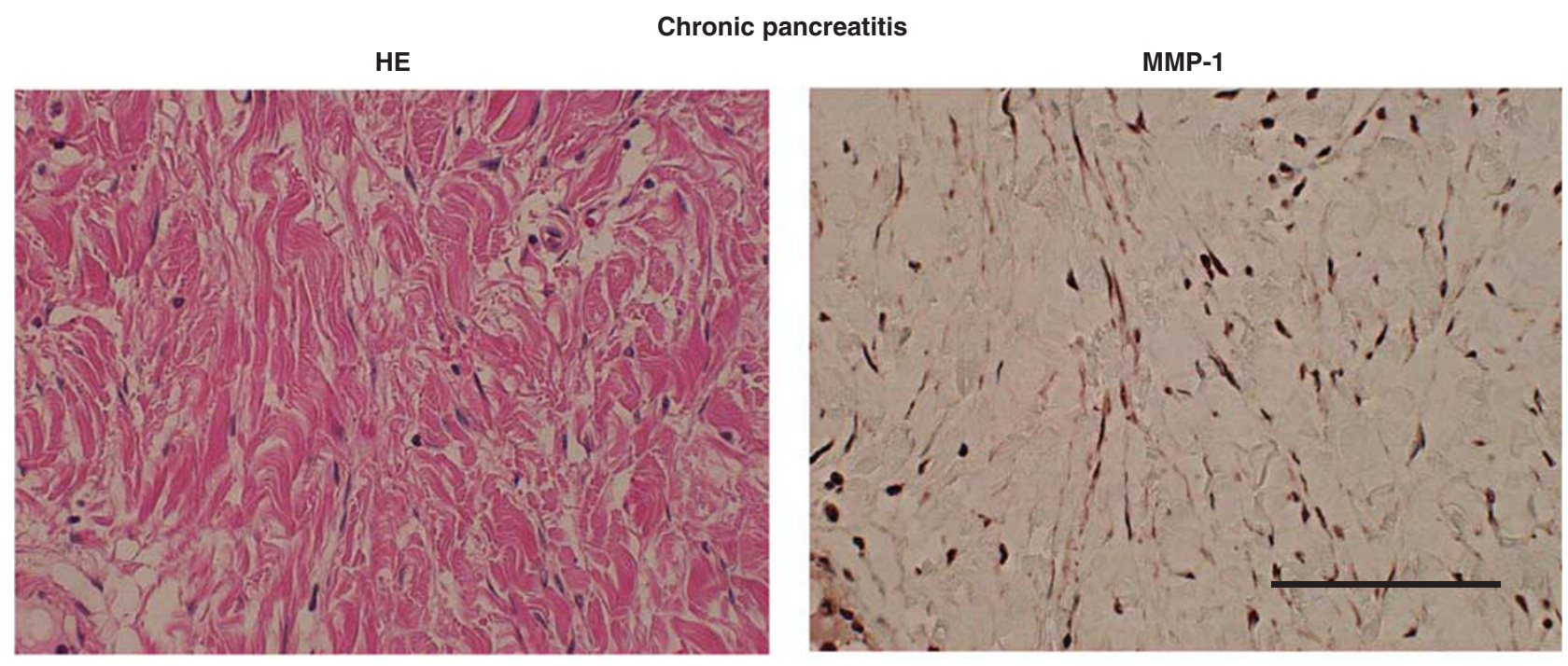

\section{$\alpha-S M A$}

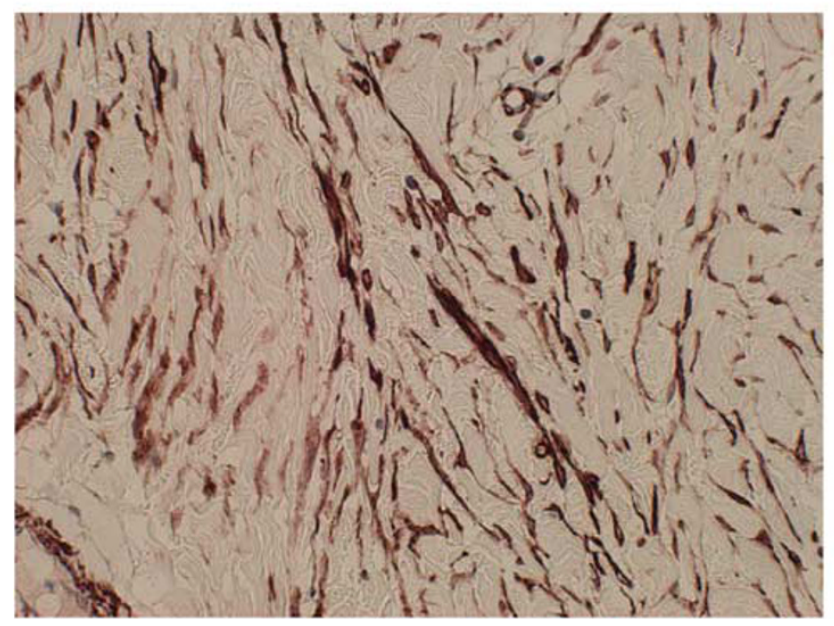

GFAP

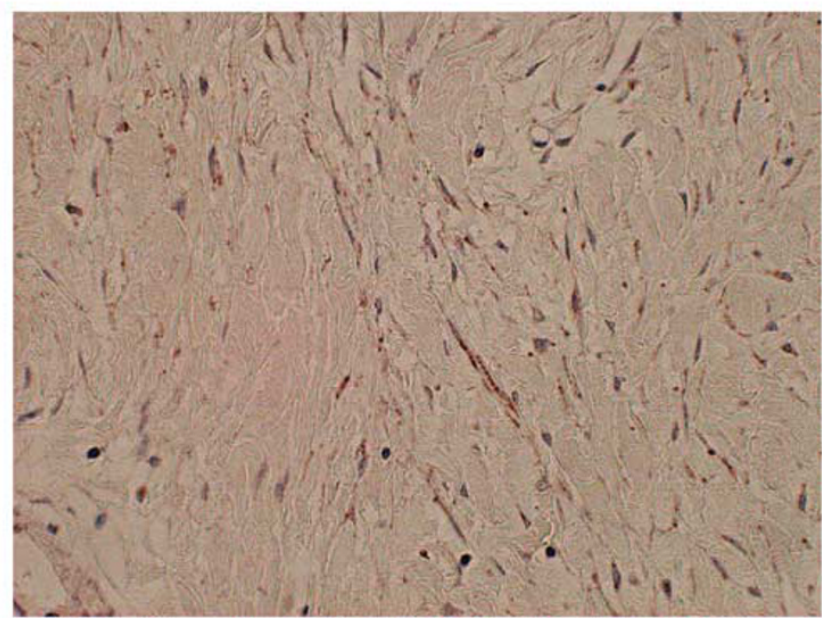

Figure 7 The distribution of matrix metalloproteinase-1 (MMP-1) in the pancreatic interstitial tissues of a chronic pancreatitis sample. MMP-1-stained areas were compared with hematoxylin-eosin (HE)-, $\alpha$-smooth muscle actin ( $\alpha$-SMA)- or glial fibrillary acidic protein (GFAP)-stained areas using the serial sections of the same tissue. Scale bar is $200 \mu \mathrm{m}$.

GFAP-stained areas (a marker of PSC identification) in the interstitial tissues of $\mathrm{CP}$ or pancreatic cancer samples, implying that MMP-1 upregulation may contribute to the pathogenesis of these clinical settings.

Surprisingly, we found that MMP-1 functional activity (ie, collagenase activity) after treatment with $50 \mathrm{nM}$ TGF- $\alpha$ was lower than that seen after treatment with $10 \mathrm{nM}$ TGF- $\alpha$, despite increased MMP-1 mRNA and protein expression levels. This discrepancy might be explained as follows. Mature MMP-1 is functional, but the precursor proMMP-1 protein is not. It is known that proMMP-1 is activated by MMP-3 (stromelysin), MMP-10, plasmin, kallikrein, and chymase, ${ }^{24,25}$ and it is possible that these activators could be inhibited by higher concentrations $(50 \mathrm{nM}$ or more) of TGF- $\alpha$. Another possibility is that MMP-1 functional activity might be affected by inhibitors other than TIMPs, such as the inhibitors of metalloproteinases, $\alpha 2$-macroglobulins, and the large inhibitor of metalloproteinase, some of which might be activated by high levels of TGF- $\alpha .{ }^{24}$

It has been shown that overexpression of TGF- $\alpha$ can cause pancreatic fibrosis in mice. ${ }^{10-12}$ This effect is consistent with our findings that TGF- $\alpha$ increases the proliferation and migration of PSCs. Considering that heparin-binding EGF reportedly regulates both chemoattraction and proliferation of PSCs through EGFR ${ }^{14}$ and that EGFR is a common receptor of TGF- $\alpha$ and heparin-binding EGF, our study supplies additional evidence on the importance of EGFR signaling in pancreatic fibrosis.

We previously showed that the effects of TGF- $\alpha$ on fibrosis or certain signal-transduction pathways could be species and/ or cell specific; ${ }^{17}$ these findings were further confirmed by this study. For example, the ERK1/2 and PI3/Akt pathways 
HE

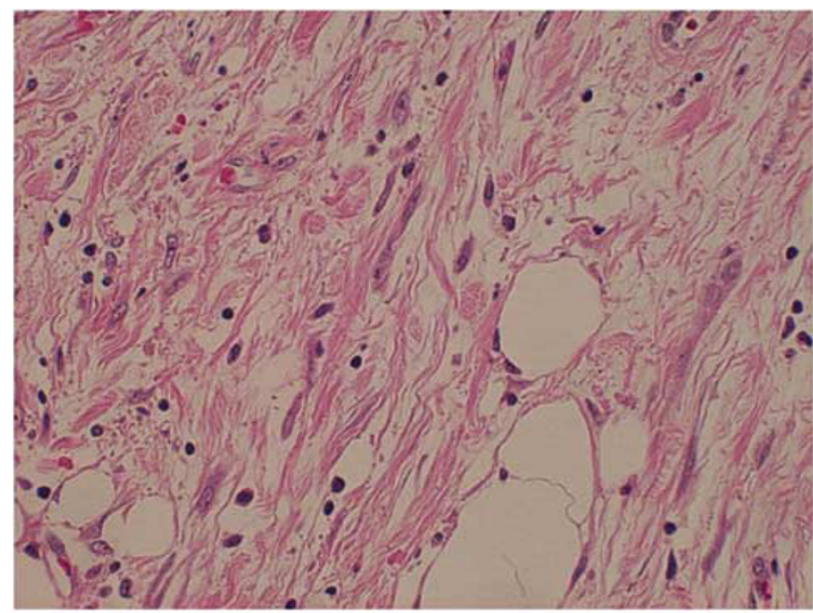

$\alpha$-SMA



\section{Pancreatic cancer}


Figure 8 The distribution of matrix metalloproteinase-1 (MMP-1) in the pancreatic interstitial tissues of a pancreatic cancer sample. MMP-1-stained areas were compared with hematoxylin (HE)-, $\alpha$-smooth muscle actin ( $\alpha$-SMA)-, or glial fibrillary acidic protein (GFAP)-stained areas using the serial sections of the same tissue. Scale bar is $200 \mu \mathrm{m}$.

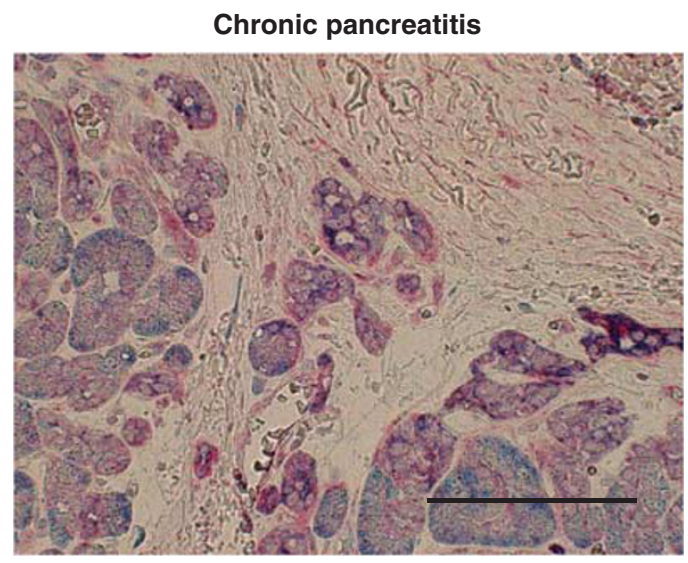

Figure 9 The partial colocalization of transforming growth factor (TGF)- $\beta 1$ and TGF- $\alpha$ in the pancreatic tissues of a chronic pancreas sample. The distribution of TGF- $\beta 1$ (red) overlapped with that of TGF- $\alpha$ (blue) in the ductal cells and a part of the acinar cells. Moreover, the TGF- $\beta 1$ expression was found in the interstitial cells. Scale bar is $200 \mu \mathrm{m}$. were involved in MMP-1 expression in the human PSC line RLT-PSC, whereas the ERK1/2, JNK, and p38 pathways are involved in MMP-1 expression in the human hepatic stellate cell line LX-2. ${ }^{17}$ In addition, it has been noted that the TGF- $\alpha$-expressing transgenic mouse line MT42 exhibits hepatocarcinogenesis without pronounced liver fibrosis but with extensive pancreatic fibrosis. ${ }^{11,26}$ Although the exact reasons for organ-specific differences in fibrosis are unknown, one possible explanation may be cell-type-specific differences in TGF- $\alpha$-induced signal transduction.

TGF- $\alpha$ and EGFR overexpression in $\mathrm{CP}^{13}$ is consistent with the observed upregulation of MMP-1 in CP in our study. The known involvement of MMP-1 in the migration of human mesenchymal stem cells ${ }^{27}$ also supports a role for MMP-1 in PSC migration. As MMP-1 has a crucial role in tumor cell invasion, ${ }^{24,28}$ and TGF- $\alpha$ is reportedly upregulated in several pancreatic cancer cell lines, ${ }^{15}$ MMP-1 upregulation in TGF- $\alpha$-activated PSCs may be important for pancreatic 
cancer cell invasion. These findings highlight the clinical importance of the inhibition of TGF- $\alpha$ action, which could decrease not only tumor cell invasion, but also decrease the suitability of PSC-induced microenvironments for cancer growth. TGF- $\alpha$ might also affect the significant crosstalk between PSCs and pancreatic carcinoma cells.

Our study has helped elucidate the role of TGF- $\alpha$ in PSCs and the potential significance of MMP-1 in pancreatic fibrosis and pancreatic cancer. However, the role of TGF- $\alpha$ might be species- and/or cell-type-specific, and the effects of TGF- $\alpha$ in these clinical settings should be evaluated in other models and/or human studies in the future.

Supplementary Information accompanies the paper on the Laboratory Investigation website (http://www.laboratoryinvestigation.org)

\section{ACKNOWLEDGEMENTS}

AM is supported by Grant-in-Aid from Japan Society for the Promotion of Science (23591008).

\section{DISCLOSURE/CONFLICT OF INTEREST}

The authors declare no conflict of interest.

1. Jaster R, Emmrich J. Crucial role of fibrogenesis in pancreatic diseases. Best Pract Res Clin Gastroenterol 2008:22:17-29.

2. Omary MB, Lugea A, Lowe AW, et al. The pancreatic stellate cell: a star on the rise in pancreatic diseases. J Clin Invest 2007;117:50-59.

3. Apte MV, Haber PS, Applegate TL, et al. Periacinar stellate shaped cells in rat pancreas: identification, isolation, and culture. Gut 1998;43:128-133.

4. Erkan M, Adler G, Apte MV, et al. StellaTUM: current consensus and discussion on pancreatic stellate cell research. Gut 2012;61: 172-178.

5. Masamune A, Watanabe T, Kikuta K, et al. Roles of pancreatic stellate cells in pancreatic inflammation and fibrosis. Clin Gastroenterol Hepatol 2009;7:S48-S54.

6. Masamune A, Shimosegawa T. Signal transduction in pancreatic stellate cells. J Gastroenterol 2009:44:249-260.

7. Bachem MG, Schneider E, Gross $\mathrm{H}$, et al. Identification, culture, and characterization of pancreatic stellate cells in rats and humans. Gastroenterology 1998;115:421-432.

8. Ikejiri $\mathrm{N}$. The vitamin A-storing cells in the human and rat pancreas. Kurume Med J 1990;37:67-81.

9. Watari N, Hotta Y, Mabuchi Y. Morphological studies on a vitamin A-storing cell and its complex with macrophage observed in mouse pancreatic tissues following excess vitamin A administration. Okajimas Folia Anat Jpn 1982;58:837-858.
10. Bockman DE, Merlino G. Cytological changes in the pancreas of transgenic mice overexpressing transforming growth factor alpha. Gastroenterology 1992;103:1883-1892.

11. Jhappan C, Stahle C, Harkins RN, et al. TGF alpha overexpression in transgenic mice induces liver neoplasia and abnormal development of the mammary gland and pancreas. Cell 1990;61:1137-1146.

12. Sandgren EP, Luetteke NC, Palmiter RD, et al. Overexpression of TGF alpha in transgenic mice: induction of epithelial hyperplasia, pancreatic metaplasia, and carcinoma of the breast. Cell 1990; 61:1121-1135.

13. Korc M, Friess $\mathrm{H}$, Yamanaka $\mathrm{Y}$, et al. Chronic pancreatitis is associated with increased concentrations of epidermal growth factor receptor, transforming growth factor alpha, and phospholipase $C$ gamma. Gut 1994;35:1468-1473.

14. Blaine SA, Ray KC, Branch KM, et al. Epidermal growth factor receptor regulates pancreatic fibrosis. Am J Physiol Gastrointest Liver Physiol 2009;297:G434-G441.

15. Beauchamp RD, Lyons RM, Yang EY, et al. Expression of and response to growth regulatory peptides by two human pancreatic carcinoma cell lines. Pancreas 1990;5:369-380.

16. Ghaneh P, Costello E, Neoptolemos JP. Biology and management of pancreatic cancer. Gut 2007;56:1134-1152.

17. Ohyama T, Yamazaki Y, Sato K, et al. Transforming growth factor-a attenuates hepatic fibrosis: possible involvement of matrix metalloproteinase-1. Liver Int 2011;31:572-584.

18. Kayed $\mathrm{H}$, Jiang $\mathrm{X}$, Keleg $\mathrm{S}$, et al. Regulation and functional role of the Runt-related transcription factor-2 in pancreatic cancer. Br J Cancer 2007;97:1106-1115.

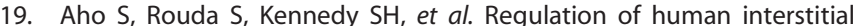
collagenase (matrix metalloproteinase-1) promoter activity by fibroblast growth factor. Eur J Biochem 1997;247:503-510.

20. Jesnowski R, Fürst $\mathrm{D}$, Ringel J, et al. Immortalization of pancreatic stellate cells as an in vitro model of pancreatic fibrosis: deactivation is induced by matrigel and N-acetylcysteine. Lab Invest 2005;85: 1276-1291.

21. Masamune A, Kikuta K, Watanabe T, et al. Fibrinogen induces cytokine and collagen production in pancreatic stellate cells. Gut 2009;58: 550-559.

22. Ohyama T, Sato K, Kishimoto $\mathrm{K}$, et al. Azelnidipine is a calcium blocker that attenuates liver fibrosis and may increase antioxidant defence. Br J Pharmacol 2012;165:1173-1187.

23. Masamune $A$, Watanabe $T$, Kikuta $K$, et al. Nuclear expression of interleukin-33 in pancreatic stellate cells. Am J Physiol Gastrointest Liver Physiol 2010;299:G821-G832.

24. Chakraborti S, Mandal M, Das S, et al. Regulation of matrix metalloproteinases: an overview. Mol Cell Biochem 2003:253:269-285.

25. Suzuki K, Enghild JJ, Morodomi T, et al. Mechanisms of activation of tissue procollagenase by matrix metalloproteinase 3 (stromelysin). Biochemistry 1990;29:10261-10270.

26. Takagi H, Sharp R, Hammermeister $C$, et al. Molecular and genetic analysis of liver oncogenesis in transforming growth factor alpha transgenic mice. Cancer Res 1992;52:5171-5177.

27. Ho IA, Chan KY, Ng WH, et al. Matrix metalloproteinase 1 is necessary for the migration of human bone marrow-derived mesenchymal stem cells toward human glioma. Stem Cells 2009;27:1366-1375.

28. Nabeshima $K$, Inoue $T$, Shimao $Y$, et al. Matrix metalloproteinases in tumor invasion: role for cell migration. Pathol Int 2002;52:255-264. 